\title{
Successful Integration of Informal Learning in Engineering Education
}

\author{
http://dx.doi.org/10.3991/ijac.v5i2.2102 \\ Lynroy Grant and Akram Abu-aisheh \\ University of Hartford, West Harford, CT, USA
}

\begin{abstract}
Research suggests that an emerging environment of ubiquitous information technology affords seamless movement between formal learning, informal learning, and the workplace. This paper reviews research data from one successful teaching and learning methodology that leverages seamless movements between informal and formal learning in engineering education. The research is an ongoing pilot study at the University of Hartford using data from selected technical mathematics and communication electronics courses. The research data suggests that clearly defined academic jurisdictions have a positive correlation with successful integration of formal learning, informal learning, and the workplace. However, themes from the data also suggest that crossing academic boundaries involves more than technology issues and could raise the specter of unintended social-dramas. One theme suggests that, in a seamless environment without clearly defined academic jurisdictions, opportunities for collaboration could be misinterpreted as encroachments. To mitigate issues of competing jurisdictional interests this study employs Learner Agent Objects (LAO) individual portfolios. LAO portfolios are collections of evidence-based artifacts representing a learner's academic experience that independently moves with the learner as data network nodes between jurisdictions in engineering education and the workplace.
\end{abstract}

Index Terms-Informal Learning, Learner Agent Object, Learner Mobility, Learner Data Nodes.

\section{INTRODUCTION}

Engineering education is not structured to meet rapidly accelerating changes in the global environment. For example, many of the 2010 top-ten employment opportunities in the United States did not exist in 2004, and this indicates that multi-directional movements between formal learning, informal learning, and the workplace for shorter periods of time will increase in order to maintain relevance [1-5]. This would indicate that to be relevant in the future, learners need to be academically engaged throughout the life of their career. To further complicate the issue The National Academy of Engineers (NEA) [2011] reports that none of the world's current major engineering challenges will be solved without collaboration from other disciplines.

Solutions to "technical and non-technical challenges are now inseparable” [1]. Literature suggests that affordances, which are activities an object allows, enables, or affords from a global digital environment have huge implications for engineering education. The emerging environment of ubiquitous information technology affords, among other capabilities, seamless movements of autonomous learners between formal learning, informal learning, and the workplace [6]. For engineering education institutions this mobility is an opportunity to provide ondemand instructions, in relevant formats, throughout a student's (learner's) career, not just during the traditional four year degree programs. For the learner this mobility means an opportunity for customizing a career, at desired pace and manner, punctuated by accessible relevant academic engagement. Based on the literature these affordances are transforming the teaching and learning process into an unprecedented, on demand, subscription based, long term partnership.

According to the literature, affordances from movements of autonomous learners have engendered many successes in engineering education but also have created many challenges and opportunities. In general, jurisdictions of formal learning, informal learning and the workplace have different, and often competing, interests. And at the moment, there is no common engineering education interdisciplinary arrangement, or set of tools, for adjudicating seamless movement of autonomous learners between these jurisdictions. There are more indications that any successful arrangement or set of tools will be part of a systemic structural transformation, more far reaching than "a mish-mash of traditional lecturing with some online content” [1].

This study also explores autonomous learning which is defined as learning anchored to a portable, enhanced, and independent environment customized to enable multiple means of representation, expression and engagement towards furthering the interest of the individual or group. This definition combines elements from the National Center on Universal Design for Learning (UDL) [8], research in foreign languages [9 \& 10], and from other areas.

Research on creating a common framework for engaging autonomous learners in engineering is limited. This gap in the literature is particularly evident for movements of autonomous learners between formal and informal academic jurisdictions. The search for more seamless collaborations is not new or unique to engineering education. According to Pieters and Baumgartner in their understanding of "who talks to whom" in both intra and interdisciplinary communication, no area of economics appears to build substantially on insights from its sister disciplines [11].

However, there are many research efforts which capitalize on new technological advances toward improving seamless interdisciplinary collaborations. One example, from among many, is to explore alternative teaching and learning environments and ecosystems in which the National Science Foundation (NSF) and the journal 
Science created the International Science and Engineering Visualization competition as a way of promoting alternative forms of communicating science, engineering and technology for education and journalistic purposes, [1213]. Another example is the collaboration of many institutions to explore opportunities of Open Courseware. However, these collaboration have been generally reactive, piecemeal, and have not resulted in major systemic change to facilitate a seamless movement of individuals within K-16 engineering education infrastructure and beyond to lifelong learning as informed citizens.

The purpose of this ongoing pilot study is to explore a proof of concept that demonstrates how to capitalize on available technology for creating a more comprehensive and seamless environment that affords on going real-time movements between formal settings and non-formal learning, and also between classroom experiences and the workplace. The ongoing pilot study is being conducted at University of Hartford's College of Engineering, Technology, and Architecture (CETA)

This second preliminary report data indicates autonomous learning makes use of a broader range of technology affordances for engineering education. Using Learner Agent Objects (LAO), individual academic portfolios simulate seamless movements of autonomous learners between formal learning, informal learning and the workplace. Indicators are increased time-on-task, emotional investment, independence, and autonomous learning.

The study has raised important questions about engineering education that require more conversations and research. This limited work only highlights the possibility that LAO could be a useful tool for accommodating transparent collaboration between the different, or competing, interests in engineering education as technology continues to enable unprecedented changes in our lives.

\section{ENGINEERING EDUCATION AND AFFORDANCES OF A DIGITAL ENVIRONMENT}

Elements used in explaining affordances of paper can be applied to engineering education. According to Sellen and Harper [6] affordances are activities an object allows, or affords. In the case of a digital environment of ubiquitous information technology, affordance is what the technology allows. However, for engineering education institutions to benefit from the full extent of what technology allows they "cannot comfortable evolve ...but instead must muster the courage to leave behind the old and redefine" new teaching and learning process for the world we are facing [8]. The challenge is that some of the old models for teaching engineers are currently productive, economically sound, and even thriving. All sound management decision would suggest staying the course. To make matters more complicated, the quality of new teaching and learning process is generally a lower standard and appeals to a "different" population. One example is the issue of quality with online engineering education.

However, Christensen, Horn and Johnson [31] argue these counter intuitive, and what may be seen as reckless business decisions, to "disrupt class" are "How Disruptive Innovation Will Change the Way the World Learns.” They believe not making these counter intuitive decisions about how to use affordances of emerging technology is the reason why once successful organizations fail. The flaw in these decisions, they argue, is their focus on how these affordances could maintain and grow their organization using current population (or increase the current population), while ignoring the potential benefits of these affordances for serving a totally different population. They believe academic institutions are at risk of making the same mistake of following conventional wisdom. The following are some issues that support their case in terms of affordances from seamless movements of autonomous learners between formal learning, informal learning and the workplace.

The academy is in search of a common process engaging movements across different, often competing, jurisdictions. There is a clear consensus in the literature that with emerging technologies, the future of engineering education involves more interdisciplinary communication and collaboration [22]. But there is silence about whose academic cultural norms, practices, and ways of knowing will be used in such collaboration. In the global economy for example, because the technology affords (allows) it, English has evolve as a common process for conducting international commerce, while respecting local languages and customs. Looking at the full spectrum of possibilities of what seamless movement of autonomous learners affords there may be a way for the academy to accommodate communication and collaboration across interdisciplinary cultures and ways of knowing while providing effective relevance to the autonomous learner. One approach is to use affordances of technology to make students (learners) full partners of the academy, which includes providing "lesser quality" to a different population. In this approach, the academy would be academically engaged with groups of autonomous learners, accountable for supporting each other for the life of their carrier. This arrangement would be similar to an academic and career marriage of sorts, and would resolve some interrelated issues which go beyond affordances of technology.

\section{AUTONOMOUS LEARNING}

There are more than technology issues to seamless movement of anomalous learners. A review of the literature reveals that emerging technology is credited with displacing traditional boundaries between types of learning, and for removing physical barriers to seamless movements between formal and informal learning communities. However, potential benefits, and side effects from affordances of seamless movements between formal and informal learning communities in a digital environment, raise interrelated questions that include but go far beyond the technology issues. For example: issues, of economics, of incentives for motivation, of authority and autonomy, of entitlement to validate and marshal authenticity, of philosophy of education, and of "legitimate" ways of knowing, are among the array of elements continuously influencing each other. Any solution for seamless engineering education teaching and learning environments must account for these influencing issues. The use of autonomous learners as the common link for communication and collaboration in the academy may be one solution. For this study, autonomous learning is defined as learning anchored to a portable, enhanced, and independent environment customized to enable multiple means of representation, expression and engagement towards furthering the interest of the individual or group. 


\section{ONGOING PILOT STUDY}

This is an ongoing pilot study for over four years in search of useful processes and best practices for educating engineers for the $21^{\text {st }}$ century [18-20]. The researchers began with the latest information about how people learn $[17,30]$, reviewed progress and accomplishments [23, 25], and the emerging meaning of engineering education are, and how to leverage affordances of technology. A first report of preliminary data was "Fostering Learner Mobility between Engineering Education and a Twenty First Century Workplace” [7], which demonstrated the proof of concept of general constructs for learner mobility, and established points of references for future work.

This paper represents a second report of preliminary data which builds on previous literature review and research data. The focus this time was articulating, and demonstrating proof of concept, that autonomous learning makes use of a broader range of technology affordances for engineering education.

The paper uses three major working assumptions. (1) Affordances of a digital environment bring new meanings to the teaching and learning process. (2) Cumulative artifacts, simulations, and meta-data can represent and influence an individual's learning experiences both in and out of the formal engineering education setting. (3) When learners control artifacts that represent their content knowledge they will invest more interest in maintaining these artifacts. Byproducts are: improved time on task, independent learning, and content revisions which are shown to be correlated with how people learn [17].

\section{THE LEARNER AgENT OBJECTIVE FrAMEWORK}

Learner Agent Objects (LAO) is not a specific technology or pedagogical methodology; rather, it is a framework of ideas for creating and transferring knowledge in a digital environment where the capability of the student (learner) transcends biology [26]. LAO aims to use the affordance of digital technology to extend our perception of the individual's capabilities to learn, work and make decisions as an informed citizen. This affordance includes continuously accumulating academic artifacts, and simulations, in a permanent personal library for supporting the individual's interaction with stakeholders in the teaching and learning process. Support capabilities are grouped in at least three categories:

1. in artifacts, simulations, and meta-data that represent and influence an individual's learning experiences both in and out of the formal engineering education,

2. in exchanging ideas with others,

3. in analyzing and solving problems. One assumption is that over time and as digital technology matures, the usefulness of this personal library or hub of knowledge would render it an extension of the individual much as a limb or organ in the teaching and learning process.

LAO is grounded in a long history of successful, but piecemeal efforts, among the disciplines in STEM education. Some of these successful but piecemeal education efforts are: First Year Interest Groups (FIG); intelligent learning systems; object-orientated education technology and related interconnectivity applications; project based learning and active learning methods; increased application of market principles in education; philosophy and ethics for digital education enterprises; and heightened interest in understanding how people learn [17]. Students (learners) are generally the only consistently common element in these piecemeal efforts, and for learners to present more complete information about their academic situation to stakeholders in STEM education is the focus of LAO.

The LAO framework draws heavily from a category of FIGs, implemented at the University of Hartford and other locations, which by design uses existing infrastructures (both physical and epistemological) to support small curricular units called Integrated Learning Blocks (ILB). However, in the wake of a critical cohort of maturing technologies reaching a practical tipping point, tools from instructional technology, computer and cognitive sciences are employed to expand the ILB concept into smart continuous learning agents. In this project, LAOs expands the one-year FIG model to include pre-college experience and the entire college years, and continues with life beyond college. Developing an LAO infrastructure provides a valuable academic hub and scaffolding for supporting life-long learning and also the potential for creating new revenue streams for higher education.

LAO raises important philosophical issues about its usefulness in creating the knowledge and ethics of a digitally extended student (learner) in a digital environment. For example, there are issues of control digital property, and compatibility. However, knowledge associated with this academic experience and other important philosophical issues are not the focus of this paper.

In addition, issues of LAO as a smart agent of the individual in a digital environment are also not the focus of this paper, and are best pursued elsewhere using existing agency theory research as a starting point for understanding issues of LAO as a digital agent of the individual learner. This is only a beginning attempt of a first step towards constructing a framework of ideas to search for solutions about how to perceive enhanced learning, and enhanced learners, in three broad areas.

1. To prepare future technologists,

2. To prepare future engineers, and

3. To provide a timely delivery system for educating the country's workforce. To demonstrate the proof-ofconcept of LAO in these three categories, Blackboard discussion board was used as a digital container where students continuously accumulate their best work from selected classes.

\section{DATA AND METHODOLOGY}

The model employs Blackboard, the university's primary course management system, and Google accounts, (knowledge containers) to simulate a seamless environment for ubiquitous information technology. For the purpose of this study references to Blackboard mean combined knowledge containers. The study used these knowledge containers or individual academic portfolios, for students' accumulative body of work. Files and applications in these containers are called Learner Agent Objects (LAO). Frequency of access to these documents was used as indicator of student interest, and content of data files were reviewed to measure level of student collaboration.

The content of the student work posted on Blackboard forms a library of reusable objects (fixed) for subsequent 
exams, assignments, and future classes. For example, from Course Statistics on Blackboard researchers were able to determine that students, and alumni, are using their posts years after a course.

An ethnographic exploratory study was started in the fall semester 2006 to test the concept of The Learner Agent Objects (LAO). Students from classes taught by selected faculty members (technical mathematics and electrical engineering) were asked initially to post their "best work" in three-ring binders used in formats required for Accreditation Board for the Engineering and Technology (ABET). However after one semester three-ring binders were replaced with posting students" "best work" on Blackboard where it could be observed by other students, faculty and staff. As of January 2009, the number of participants in the study is 200. Participants taking multiple courses were counted once.

Rubrics for class assignments and tests were created for the LAO framework for each class. In general, tests and class assignments were returned to the students with a grade. However, grades are not official until students make the necessary corrections to their work and post the edited content (best work) on Blackboard (grades are not included). Because of the limitations of the drop-box feature, a separate Blackboard class was created with one discussion board for all students to share their work. Each student would create one thread with his or her names, and then reply to his or her names attaching a file with his or her best work (Microsoft Word, text, graphics, videos, or PDF files). Each file on average contains material covered by a major topic or chapter of the textbook. For example, one file may contain three completed problems from each section of a textbook chapter, with full explanations of each step.

High level of expertise is expected from the student who presents his or her best work. That is, the focus is not on the source of the content, or what help the student received compiling the content but instead the focus is placed on how well the student can explain and can apply the content that is presented. For this study, students are expected to be tested at any time, and in different forms, about the material they post on Blackboard. This expectation of mastery, or ownership, of posted material is not just confined to faculty, or students in the class, but to others involved in the academic life of the student.

Training is provided on how to use textbooks and other resources. Specifically, training involves learning to read the examples in the text first before doing the exercises. Training also involves learning how to maintain, and apply content to other related areas. For example, it helps the student combine different class contents and content from other disciplines, into a continuous and meaningful whole.

Faculty members are encouraged to use the posting on Blackboard as one way of understanding the academic history of their students, as well as using the posted material as a way of linking to what students already know. Not only works of students are posted in the area but sample solutions by faculty and other reference material is also posted.

Initially, the number of one-on-one student teacher conferences relating to these activities increased by more than $70 \%$ with conference time averaging 25 minutes. Since the initial semester, student conferences have been de- creasing by an average of $4.8 \%$ each semester, with the average time of conferences decreasing by $6 \%$ each semester. In September 2008 the average conference time was 15 minutes. A conference management system was used to track details of the conferences (purpose of conference, start time, stop time, comments, location, number of students etc.).

\section{PREMILINARY RESULTS}

Using primitive or static LAO artifacts (Microsoft Word, PDF and Text files) to represent best work of selected CERA (400) generated significant student to student, and faculty-to-student activity in relation to what the literature considered seven best practices in teaching [27-29]:

1. Increasing faculty-student interaction. Facultystudent interaction tends to be shorter but more frequent. Major reasons for the interactions include acting as referee for competing ideas in class projects, as consultant in solving a mathematics problem, and as a negotiator with students working for a better grade.

2. Fostering collaboration among students and providing prompt feedback. Students perceive having casual conversation about technical mathematics problem with their peers as exotic enough to merit curious inquiry. Patterns of understanding course content sometimes display a "viral" effect similar to YouTube or Wikipedia, and are more effective in communicating some technical ideas than traditional approaches.

3. Encouraging active learning and emphasizing time on task. Posting best work encourages more active participation in class work, increases attention to detail, and adds more relevance to technical mathematics.

4. Communicating high expectations while addressing different learning styles. The idea of posting class assignments after they are graded and edited allows students with different learning styles to produce the same high quality products.

Before the end of the first semester student activities quickly took on a combined YouTube and Wikipedia effect where posting best work from class assignments, special projects, and related materials became a symbol of competitive pride, a focus of social drama, and academic collaborations across subject areas and some university programs.

Some examples of social dramas include:

1. Students would challenge other's ability to do the work they posted. As such posting class content brought social status, but also the responsibility of justifying one's knowledge of the subject.

2. Communication about what was covered in previous classes improved, given that samples of the material were accessible and available to all interested parties in the teaching and learning process.

3. Time on task improved as measured by the Blackboard statistics. Students used the area all hours of the day with the period of time of 12 hours before classes recording the highest usage.

Samples of collaboration include the following: 
1. Instances of students working with each other have increased. From observation, conversation about posting work, or questions about work posted and other out of class activities started occurring only after students start posting their work on Blackboard and realize they were actually writing questions for their own examination.

2. Student-student interaction about class content increased significantly, and some questions that were directed at faculty were directed to other students leaving space for different questions and issues for the faculty to handle. In addition, with their work posted on Blackboard, students found it easier to find other pedagogical resources.

3. Maintaining an atmosphere of individualized on demand instruction required extra time and resources. The same energy that motivated students to collaborate could quickly become distracting if faculty or qualified resources were not available to adjudicate conflicts, lack of information or other related issues.

4. Having libraries of students' best work also improved early warning collaboration among faculty and staff. For example, students who were having problems, for one reason or another, generally have significantly less work to show.

Preliminary results from the CETA LAO pilot study using Blackboard show:

1. Increased faculty-student interaction,

2. Improved student-to-student collaboration leading to a "viral" effect similar to YouTube or Wikipedia which is more effective in communicating some technical ideas than traditional approaches.

3. Encouragement of active learning and an emphasis on time on task.

4. Communication of high expectations while addressing different learning styles.

LAO is a work in progress, and more work is needed to document the full benefits smart learner agents bring to all areas of our digitized academic environment. Preliminary data from CETA student on Blackboard demonstrates LAO's proof of concept in five general areas:

1. Reducing piecemeal fragmentations in education toward a seamless whole,

2. Creating echo systems of sharable best practices

3. Providing better costs analysis in education,

4. Creating new higher education revenue streams and

5. Enabling interdisciplinary stakeholders of the learner to collaborate in their native academic ways of knowing and doing in the education process.

\section{VIII.SUMMARY AND CONCLUSIONS}

This study introduced the concept of LAO as a digital container for artifacts and simulations of CETA students' (learners) academic experiences as only the beginning step in a long process of research, conversations and negotiations towards a fundamental understanding of designing learning environments for future engineers that create the output we desire. The concept of autonomous learning was introduced to describe users of LAO who bring selfinterest to a broader range of technology affordances for engineering education.
The results from this exploratory study show proof of concept that LAO has the potential for improving STEM education in five general areas:

1. Collaboration between selected technical mathematics and electrical engineering education towards a seamless whole,

2. Echo systems of sharable best practices (including ethics or collaboration in a digital education environment),

3. Pedagogical relationships in the teaching and learning process,

4. Potential for creating new higher education revenue streams and

5. Interdisciplinary stakeholders of the learner to collaborate in their native academic ways of knowing and doing in the education process.

The study also indicates that the LAO's framework has implications on different levels in the teaching and learning process [20-23]. At the classroom level, students are encouraged to use appropriate (native) technology for communicating their understanding of content. At the institutional and community levels the LAO framework provides building blocks for multidisciplinary collaboration while affirming native academic dialects and ways of knowing, diverse interests, and multiple levels of participants. This shared system of best work evolves throughout the learner's academic life-cycle and creates a practical way for integrating lifelong SETM learning into our current higher education system.

\section{REFERENCES}

[1] Peercy, Paul, and Cramer, Steven. (2011). "Redefining Quality in Engineering Through Hybred Instruction.” . Journal of Engineering Education: 100(4), pp. 625-629.

[2] Bell, Philip, Bruce Lewenstein, Andrew W. Shouse, and Michael A. Feder, Editors. Learning Science in Informal Environments: People, Places, and Pursuits. Washington, DC: The National Academies Press, 2009.

[3] Fenichel, Marilyn and Heidi A. Schweingruber; National Research Council. Surrounded by Science: Learning Science in Informal Environments. Washington, DC: The National Academies Press, 2010.

[4] Shouse, A.W. Lewenstein, B. Feder, M.A., \& Bell, P (2010). "Crafting Museum Experiences in Light of Research on Learning: Implications of the National Research Council's Report on Informal Science Education.” Curator, 53(2), pp. 137-153. http://dx.doi.org/10.1111/j.2151-6952.2010.00015.x

[5] Mote, C. D (2011). "Strategic issues facing public public universities. Paper presented at The American Association for the Advancement of Science (AAAS) Annual Meeting, Washington, DC.

[6] Sellen, Abigail \& Harper, Richard. (2003). "The Myth of the Paperless office”. MIT. Boston, MA.

[7] Ahmad Abu-aisheh, Akram \& Grant, Lynroy (2010), "Fostering Learner Mobility between Engineering Education and a Twenty First Century Workplace,” International Journal of Advanced Corporate Learning (iJAC), Vol 4, No 2 (2011) pp. 4-8.

[8] National Center on Universal Design for Learning (UDL) (2011). UDL At A Glance. Retrived from http://www.udlcenter.org/ aboutudl/whatisudl/conceptofudl

[9] Holec, H., 1981: Autonomy and foreign language learning. Oxford: Pergamon. (First published 1979, Strasbourg: Council of Europe)

[10] Little, David. (210). "Learner autonomy and second/foreign language learning." Centre for Languages, Linguistics and Area Studies. Retrieved 7 October 2011, from http://www.llas.ac.uk/ resources/gpg/1409 
[11] Pieters, Rik, and Baumgartner, Hans. (2002). "Who Talks to Whom? Intra- and Interdisciplinary Communication of Economics Journals”. Journal of Economic Literature: 40(2), pp. 483-509. http://dx.doi.org/10.1257/002205102320161348

[12] Alabanese M., \& Mitchell, S. "Problem-based learning: a review of literature on its outcomes and implementation issues," Academic Medicine, Vol. 68, 1993, No. 1.

[13] Baker, D. A., \& Witt, P. A. (1995). Evaluation of the impact of two after-school programs. Journal of Park and Recreation Administration, 14(3), 60-81.

[14] Huang, R. X., M. A. Cane, N. Naik, and P. Goodman (2000), Global adjustment of the thermocline in response to deepwater formation, Geophys. Res. Lett., 27(6), 759-762 http://dx.doi.org/ 10.1029/1999GL002365

[15] Wang, M. C., Haertel, G. D., \& Walberg, H. J. (1993). Toward a knowledge base for school learning. Review of Educational Research, 63(3), 249-294.

[16] Learning Processes Task Group. (2007). National Mathematics Advisory Panel Progress Report. United States Department of Education.

[17] Donovan, Suzanne, John D. Bransford, and James W. Pellegrino, (Eds.). How people learn: bridging research and practice. Committee on Learning Research and Educational Practice, Commission on Behavioral and Social Sciences and Education, National Research Council.

[18] [18] National Research Council, Rising above the gathering storm: Energizing and employing America for a brighter economic future, Washington, DC: National Academies Press, 2005.

[19] [19] National Academy of Engineering, The engineer of 2020, Washington, DC: National Academies Press. 2004.

[20] National Academy of Engineering, Educating the engineer of 2020: Adapting engineering education to the new century, Washington, DC: National Academies Press, 2005.

[21] [21] Watson, K. "Change in Engineering Education: Where Does Research Fit? Journal of Engineering Education 98 (1): 3-4., 2009, 3.

[22] Sheppard, S. D., W. J. Pellegrino, M. B. Olds, “On Becoming a 21st Century Engineer”, Journal of Engineering Education 97 (3): 231-38, 2008, 231

[23] Huang, D. (2001). An after-school evaluation system for middle and high school programs. NAASP Bulletin, 45(626), 45-61. http://dx.doi.org/10.1177/019263650108562605

[24] Pieters, R., and Baumgartner, H. "Who Talks to Whom? Intraand Interdisciplinary Communication of Economics Journals." Journal of Economic Literature: 40(2), pp. 483-509, 2002, 2.

[25] Center for the Advancement of Scholarship on Engineering Education (CASEE). (2005-2006). "Progress and Accomplishments: Engineering Education Research and Development”: Washington, DC: National Academy of Engineering.

[26] Kurzweil, Ray. (2005) The Singularity is near: when humans transcend biology. Penguin Group. New York, New York.

[27] Chickering, Arthur and Stephen C. Ehrmann (1996), "Implementing the Seven Principles: Technology as Lever," AAHE Bulletin, October, pp. 3-6.
[28] Chickering, A.W., \& Gamson, Z.F. (1987). Seven principles for good practices in undergraduate education. "American Association of Higher Education Bulletin”, 3-7.Gibson, J. J. (1986). “The Ecological Approach to Visual Perception”. Lawrence Erlbaum Associates, Inc. Hillside, New Jersey.

[29] Alabanese M., "Problem-Based Learning: why curricular are likely to show little effect on knowledge and clinical skills," Medical education, Vol. 34, No.9, 2000, P.729. http://dx.doi.org/ 10.1046/j.1365-2923.2000.00753.x

[30] Bransford, J., A. Brown, and R. Cocking. How people learn: Brain, mind, experience, and school. Washington, DC: National Academy Press, 1999.

[31] Christensen, Clayton, Michael Horn, and Curtis Johnson. (2008). Disrupting Class: How Disruptive Innovation Will Change the way the world Learns. McGraw-Hill: New York, NY.

[32] Gabriele, G. 2005. Advancing engineering education in a flattened world. Journal of engineering Education: 94(2):3-5.

[33] Gibson, J. (1986). "The Ecological Approach to Visual Perception”. Lawrence Erlbaum Associates, Inc. Hillside, New Jersey.

\section{AUTHORS}

LYNROY GRANT is an Assistant Professor of Technical Mathematics and Engineering Simulation at the University of Hartford where he has developed the evidence based Learner Agent Objects (LAO) methodology to foster mobility in twenty-first century engineering education. Dr. Grant has a doctorate in Education and Mathematical Sciences from the University of Connecticut, and Master of Science in Mathematics and Computer Science from Central Connecticut State University. Dr. Grant may be contacted at LYGRANT@HARTFORD.EDU.

AKRAM ABU-AISHEH is an Associate Professor of Electrical and Computer Engineering at the University of Hartford where he has served as the assistant chair of the Electrical and Computer Engineering Department and director of the electronic and computer engineering technology program for two years. Professor Abu-aisheh has a doctorate in Optical Communications from the Florida Institute of Technology and Master of Science and Bachelor of Science degrees in Electrical Engineering from the University of Florida. Professor Abu-aisheh has ten years of industry experience in the US including five years as a senior member of the technical staff at Tyco Telecommunications. His research interests include Fiber Optic Communications, Solar Energy, Power Electronics, and Engineering Education. He has published a book, a book chapter, and several international journals and conference papers. Dr. Abu-aisheh may be contacted at abuaisheh@hartford.edu

Received 28 April 2012. Published as resubmitted by the authors 1 June 2012. 